\title{
Growth Morphologies of Fe Nanoparticles in the Copper Alloy
}

\author{
Yahong Zheng 1, 2, a , Zidong Wang ${ }^{1, b}$, Guodong Shi, c \\ ${ }^{1}$ School of Materials Science and Engineering, University of Science and Technology Beijing, \\ Beijing 100083, China \\ ${ }^{2}$ Wuxi Open University, Jiangsu Wuxi 214011, China \\ azhengyh1963@163.com, bwangzd@mater.ustb.edu.cn, cwangzd@mater.ustb.edu.cn
}

Keywords: Copper alloy; Nanoparticles; Morphological characteristics; Epitaxial relationship Abstract: In this paper, based on experiments, by study the nanoparticles crystallized in $\mathrm{Cu}-\mathrm{Fe}$ alloy, research possibility to form situ nanoparticles dispersion in matrix of immiscible $\mathrm{Cu}-\mathrm{X}$ alloy. Nanoparticles of Fe-rich dispersed in copper alloy were obtained by experimental methods. Confirmed by adding elements Fe (1-3\%) and Co and by thermodynamic controlling, Fe-rich nanoparticles dispersed in matrix of the copper cast alloy can be obtained. It is proved that these $\mathrm{Fe}$-rich nanoparticles and the $\mathrm{Cu}$-matrix phase remains coherency relationship.

\section{Introduction}

$\mathrm{Cu}-\mathrm{X}(\mathrm{X}=\mathrm{Fe}, \mathrm{Co}, \mathrm{Cr}, \mathrm{Ta}, \mathrm{Nb}$, etc.) are metastable immiscible alloys [1], they have broad application prospects when the $\mathrm{X}$-rich phase dispersed in the $\mathrm{Cu}$-matrix when $\mathrm{Cu}$ is richer than $\mathrm{X}$ element of these alloys [2-4]. However, since the segregation structure easily formed during solidification of these alloys, their application has been limited. Phase diagrams of $\mathrm{Cu}-\mathrm{X}$ metastable immiscible alloys have similarity, typical phase diagram of metastable immiscible binary alloys is shown in Fig.1. (a), below the liquids line, there is a immiscible liquid area consist of the metastable phase. When the degree of undercooling is small, the melt liquid occurs liquid-solid phase transform, but the degree of undercooling is larger, the alloy melt liquid is into the immiscible liquid area, and it forms two immiscible liquid: $\mathrm{Cu}$-rich liquid phase (L1) and X-rich liquid phase (L2). Now, people studied $\mathrm{Cu}-\mathrm{X}$ alloys especially studied $\mathrm{Cu}-\mathrm{Fe}$ and $\mathrm{Cu}-\mathrm{Co}$ metastable immiscible alloys [4-7], but the research work focuses on thermodynamics.
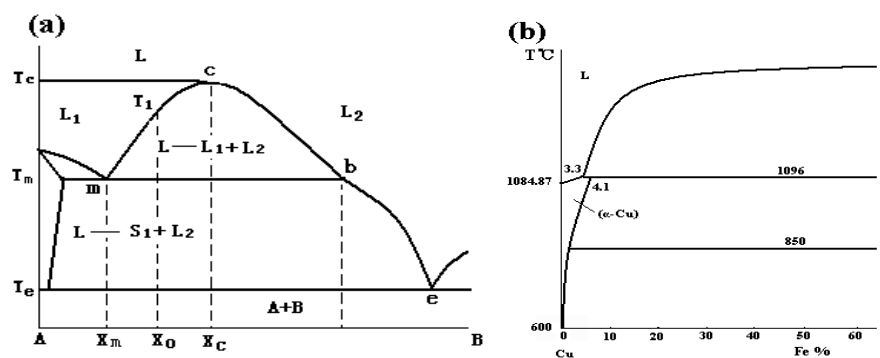

Fig.1. (a) Typical phase diagram of metastable immiscible binary alloys; (b) $\mathrm{Cu}-\mathrm{Fe}$ phase diagram

In this paper, based on experiments, by study the nanoparticles crystallized in $\mathrm{Cu}-\mathrm{Fe}$ alloy, research possibility to form situ nanoparticles dispersion in matrix of immiscible $\mathrm{Cu}-\mathrm{X}$ alloy. Analyze changes of morphology and distribution of nanoparticles in $\mathrm{Cu}-\mathrm{Fe}$ alloy when the content changes of alloying element $\mathrm{Fe}$ and $\mathrm{Co}$ and the natural convection changes in crystal process.

\section{Nanoparticles in copper alloys}

As shown in Fig.1. (b), According to $\mathrm{Cu}-\mathrm{Fe}$ phase diagram under equilibrium solidification conditions [8], the solidification process of $\mathrm{Cu}-\mathrm{Fe} \quad(\mathrm{Fe}<3.3 \%)$ alloy can be described as, when the temperature of the alloy melt dropped below the liquidus line, primary $\alpha$-Cu crystallized from the liquid phase. When the temperature of the alloy dropped below the solidus line, the remaining liquid would completely converted to $\alpha-\mathrm{Cu}$. As the temperature continues to drop, Fe will separate out from 
$\alpha-\mathrm{Cu}$ in $\mathrm{Cu}-\mathrm{Fe}$. However, quantitative number of our experiments showed that Fe particles can also crystallize from melted liquid directly, the final form of $\mathrm{Fe}$ is nanoparticles dispersed in the matrix of the alloy.

\section{Experimental equipment}

A vacuum induction furnace was used in the experiment, having temperature measurement, supplementary feeding, trace elements feeding and other functions. It does not destroy vacuum situation of furnace room, having filling with inert gas to furnace room to control the furnace pressure and atmosphere at the same time. Casting shapes in the experiment were quartz tubes with diameters of $3 \mathrm{~mm}$ and $6 \mathrm{~mm}$. There is a small natural convection during solidification in $6 \mathrm{~mm}$ diameter quartz tube and convection is negligible when solidification in $3 \mathrm{~mm}$ diameter quartz tube [9]. Vacuum induction furnace is smelting equipment under vacuum or under gas protection conditions. By the action of alternating current induction, the metal furnace charge in the crucible itself heating and melting, and further the metal liquid overheating. Vacuum induction furnace main technical parameters as shown on Tab. 1.

Tab. 1. Main technical parameters of the vacuum induction furnace

\begin{tabular}{cccc}
\hline Items & Parameters & Items & Parameters \\
\hline capacity & $10 \mathrm{Kg}$ & Rated IF frequency & $4000 \mathrm{~Hz}$ \\
Maximum operating temperature & $1700^{\circ} \mathrm{C}$ & Intermediate frequency voltage & $300 \mathrm{~V}$ \\
Maximum vacuum & $6 \times 10^{-3} \mathrm{~Pa}$ & Cooling water consumption & $9 \mathrm{~m}^{3} / \mathrm{h}$ \\
Pressure rise rate & $4 \mathrm{~Pa} / \mathrm{h}$ & Cooling water pressure & $0.3 \mathrm{MPa}$ \\
\hline
\end{tabular}

\section{Distribution and size of the nanoparticles in alloy}

Figure 2 is TEM images of $\mathrm{Cu}-\mathrm{Fe}$ cast alloys solidified in $3 \mathrm{~mm}$ diameter quartz tube. In this condition, the diameter of quartz tube is too small, so convection is neglect [9]. As Fig. 2 (a), it is $\mathrm{Cu}-1 \mathrm{Fe}$ (Fe content is $1 \%$ ) alloy, there are a large number of dispersed nanoparticles in the matrix, these nanoparticles can be divided into two classes, the first type nanoparticle's size is 5-10 nm (for example in the area I), dispersed in the matrix; the other type nanoparticle's size is about $25 \mathrm{~nm}$ (for example in the area II), dispersed in the matrix.

Figure 2 (b) compares with Fig. 2 (a), with the increase of content of Fe, particles in the matrix occurred changes on size and morphology. According to the size and shape, particles in $\mathrm{Cu}-1.5 \mathrm{Fe}$ alloy can be divided into three types, the first type of nanoparticle' s size is $5-10 \mathrm{~nm}$ (for example in the area I), it dispersed in the matrix; the second type of nanoparticle's size is 50-80 nm (for example in the area II), disc-shaped and dispersed in the matrix; the third type of nanoparticle' s size is about 170-300 $\mathrm{nm}$ ( for example in the area III), petaloid and dispersed in the matrix.

Figure 2 (c) compares with Fig. 2 (b), content of Fe is increased from $1.5 \%$ to $2 \%$, but the difference of distribution and size of the nanoparticles is very small.

Figure 2 (d) is TEM of $\mathrm{Cu}-1 \mathrm{Fe}-0.5 \mathrm{Co}$ (Fe content is $1 \%$, Co content is $1.5 \%$ ) cast alloy. Comparison shows, size and morphology of the particles in the matrix occurred large changes as a result of adding the element Co. As shown, there are a large number of dispersed nanoparticles on the matrix. These nanoparticles can be divide into four classes, the first class nanoparticles' size is 5-10 $\mathrm{nm}$ ( for example in the area I), dispersed in the matrix; the second class nanoparticles' size is about $20 \mathrm{~nm}$ (for example in the area II), disc-shaped, and twins phenomenon began to appear (please see 2.6); the third class nanoparticles' size is about $100 \mathrm{~nm}$ ( for example in the area III), disc-shaped dispersed in the matrix. The fourth class nanoparticles' size is greater than $150 \mathrm{~nm}$ ( for example in the area IV), and the shape has become typical petals. 

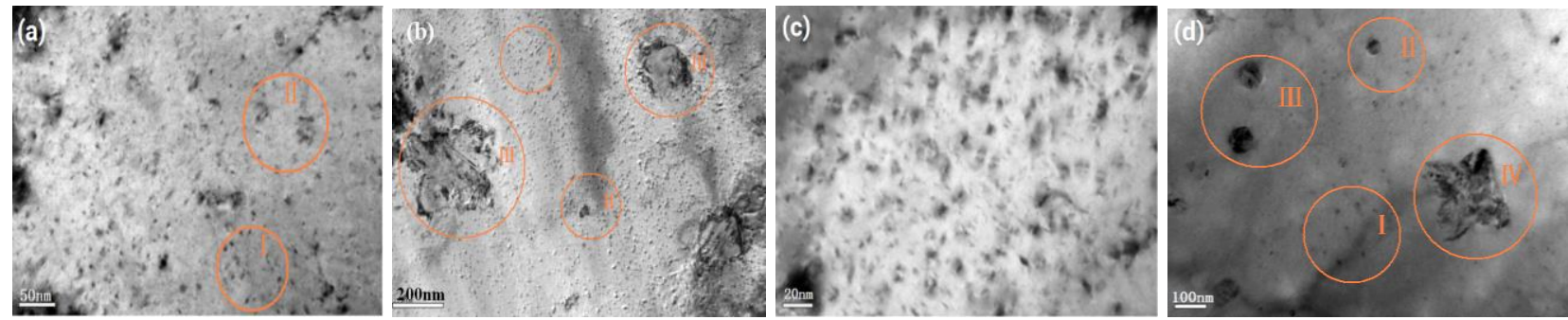

Fig.2. TEM images of $\mathrm{Cu}-\mathrm{Fe}$ cast alloys solidified in $3 \mathrm{~mm}$ diameter quartz tube

\section{Composition of the nanoparticles}

(a) $\mathrm{Cu}-1 \mathrm{Fe}$ alloy; (b) $\mathrm{Cu}-1.5 \mathrm{Fe}$ alloy; (c) $\mathrm{Cu}-2 \mathrm{Fe}$ alloy; (d) $\mathrm{Cu}-1 \mathrm{Fe}-0.5 \mathrm{Co}$ alloy

As shown in Fig. 3(a) and Fig. 4(a), EDS analysis aimed a larger precipitated phase in $\mathrm{Cu}-1 \mathrm{Fe}$ alloy as shown in Fig. 1(a) and Cu-1Fe-0.5Co alloy as shown in Fig. 1(d). 91.48\% of content of precipitated phase in $\mathrm{Cu}-1 \mathrm{Fe}$ alloy is element $\mathrm{Fe}, 8.52 \%$ the remainder being $\mathrm{Cu}$. $60.98 \%$ of content of precipitated phase in $\mathrm{Cu}-1 \mathrm{Fe}-0.5 \mathrm{Co}$ alloy is element $\mathrm{Fe}, 25.95 \%$ is element $\mathrm{Co}$, the remainder being $\mathrm{Cu}$. Precipitated phase particles in alloys are rich in $\mathrm{Fe}$, element $\mathrm{Co}$ and $\mathrm{Cu}$ are solid solution in $\mathrm{Fe}$ particles during solidification process. Therefore, these precipitates may be referred Fe nanoparticles.
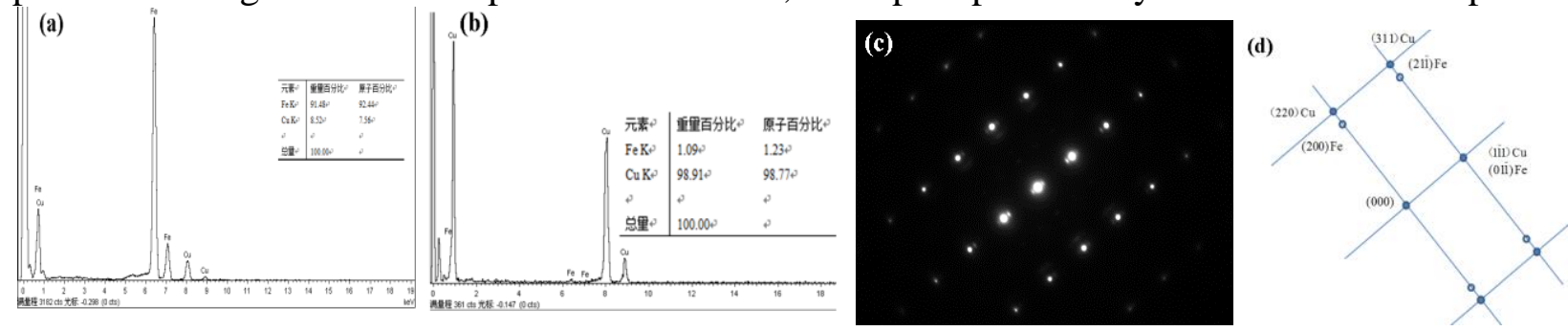

Fig. 3. EDS and diffraction pattern of Cu-1Fe alloy solidified in $3 \mathrm{~mm}$ diameter quartz tube (a) EDS of matrix of $\mathrm{Cu}-1 \mathrm{Fe}$ alloy; (b) EDS of an nanoparticle of $\mathrm{Cu}-1 \mathrm{Fe}$ alloy; (c), (d) Diffraction pattern and its calibration of $\mathrm{Cu}-1 \mathrm{Fe}$
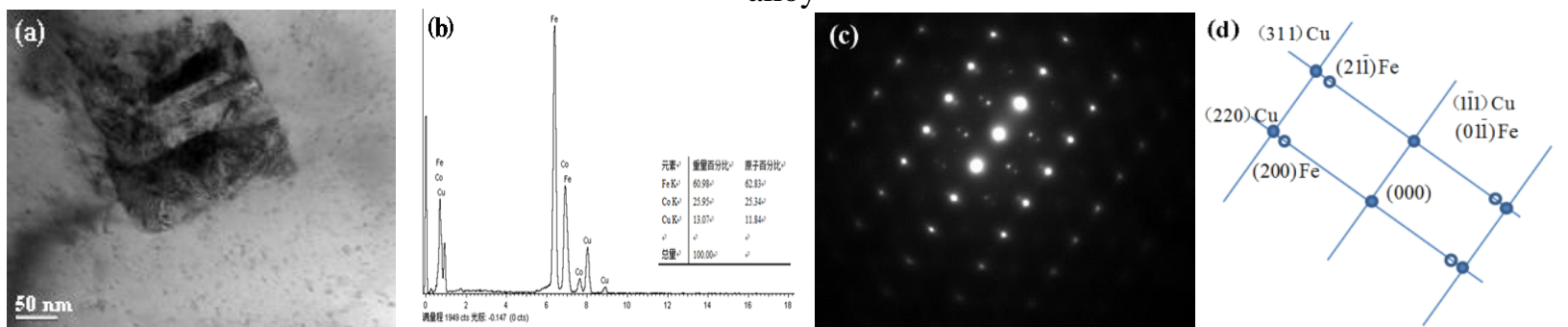

Fig. 4. EDS and diffraction pattern of $\mathrm{Cu}-1 \mathrm{Fe}-0.5 \mathrm{Co}$ alloy solidified in $3 \mathrm{~mm}$ diameter quartz tube (a) $\mathrm{Cu}-1 \mathrm{Fe}-0.5 \mathrm{Co}$ alloy; (b) EDS of an nanoparticle of Cu-1Fe-0.5Co alloy; (c), (d) Diffraction pattern and its calibration of $\mathrm{Cu}-1 \mathrm{Fe}-0.5 \mathrm{Co}$ alloy

\section{Relationship between Fe-rich phase and the matrix phase}

Diffraction pattern of area and spots in $\mathrm{Cu}-1 \mathrm{Fe}$ alloy is shown in Fig. 3 (b), the diffraction spots calibration is shown as Fig. 3 (c), the large, strong bright diffraction spots are the matrix of copper, the weaker spots are precipitated Fe-rich nanoparticles, because of (1-11) $\mathrm{Cu} / /(01-1) \mathrm{Fe}$, so a fully coherent relationship presence between $\mathrm{Cu}$-matrix and Fe-rich particles in $\mathrm{Cu}-1 \mathrm{Fe}$ alloy.

Diffraction pattern of area and spots in $\mathrm{Cu}-1 \mathrm{Fe}-0.5 \mathrm{Co}$ alloy is shown in Fig. 4 (b), the diffraction spots calibration is shown as Fig. 4(c), the large, strong bright diffraction spots are the matrix of copper, the weaker spots are precipitated Fe-rich nanoparticles, (1-11) $\mathrm{Cu} / /(01-1) \mathrm{Fe}$ as shown in Fig. 4(c), so a fully epitaxial relationship presence between $\mathrm{Cu}$-matrix and Fe-rich particles in $\mathrm{Cu}-1 \mathrm{Fe}-0.5 \mathrm{Co}$ alloy too.

\section{Morphology of the nanoparticles}

Fig. 5 are TEM images of Fe-rich precipitates in $\mathrm{Cu}-2 \mathrm{Fe}$ alloy solidified in $3 \mathrm{~mm}$ or in $6 \mathrm{~mm}$ diameter quartz tubes, the size of precipitates are about 150 400nm. Compare Fig. 5 (a) and Fig. 5 (c), when the size of precipitates is about $150 \mathrm{~nm}$, the boundary of the Fe-rich precipitate in $\mathrm{Cu}-2 \mathrm{Fe}$ alloy solidified in $3 \mathrm{~mm}$ diameter quartz tube is relatively smooth, while the boundary of the Fe-rich precipitate in $\mathrm{Cu}-2 \mathrm{Fe}$ alloy solidified in $6 \mathrm{~mm}$ diameter quartz tube is obvious concavity (arrows Point to). When the size of precipitates is larger than $350 \mathrm{~nm}$, the shape of Fe-rich precipitates in $\mathrm{Cu}-2 \mathrm{Fe}$ 
alloy solidified in 3mm diameter quartz tube become typical petaloid, as shown in Fig. 5 (b) ; and the shape of Fe-rich precipitates in $\mathrm{Cu}-2 \mathrm{Fe}$ alloy solidified in $6 \mathrm{~mm}$ diameter quartz tube is also petaloid and appears fusing appearance (an arrow Points to), as shown in Fig. 5 (d) .
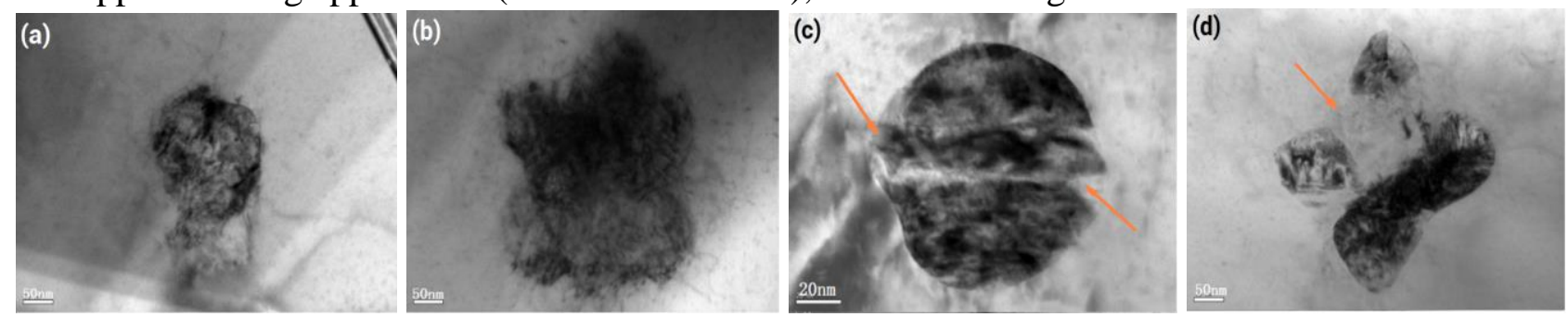

Fig. 5. TEM images of $\mathrm{Cu}-\mathrm{Fe}$ cast alloys

\section{Twin structure of the nanoparticles}

(a), (b) Fe-rich phase of $\mathrm{Cu}-2 \mathrm{Fe}$ alloy solidified in $3 \mathrm{~mm}$ diameter quartz tube

(c), (d) Fe-rich phase of $\mathrm{Cu}-2 \mathrm{Fe}$ alloy solidified in $6 \mathrm{~mm}$ diameter quartz tube

Figure 6 show twin crystal structure of Fe-rich phase from TEM images and diffraction spots of Fe-rich phase in $\mathrm{Cu}-1.5 \mathrm{Fe}$ alloy or in $\mathrm{Cu}-1.5 \mathrm{Fe}-0.5 \mathrm{Co}$ alloy solidified in $3 \mathrm{~mm}$ diameter quartz tubes. By analysis of diffraction spots to the Fe-rich phase their size are about $170 \mathrm{~nm}$ as shown in Fig. 6(a) and Fig. 6(b). As shown in Fig. 6(c), twin plane of the Fe-rich phase of $\mathrm{Cu}-1.5 \mathrm{Fe}$ is (112), but in the $\mathrm{Cu}-1.5 \mathrm{Fe}-0.5 \mathrm{Co}$ alloy, diffraction spots of the Fe-rich phase form rings as shown in Fig. 6(d).

Therefore, it is considered from diffraction spots that anisotropy of the Fe-rich phase added Co element is larger than the Fe-rich phase no added Co element.
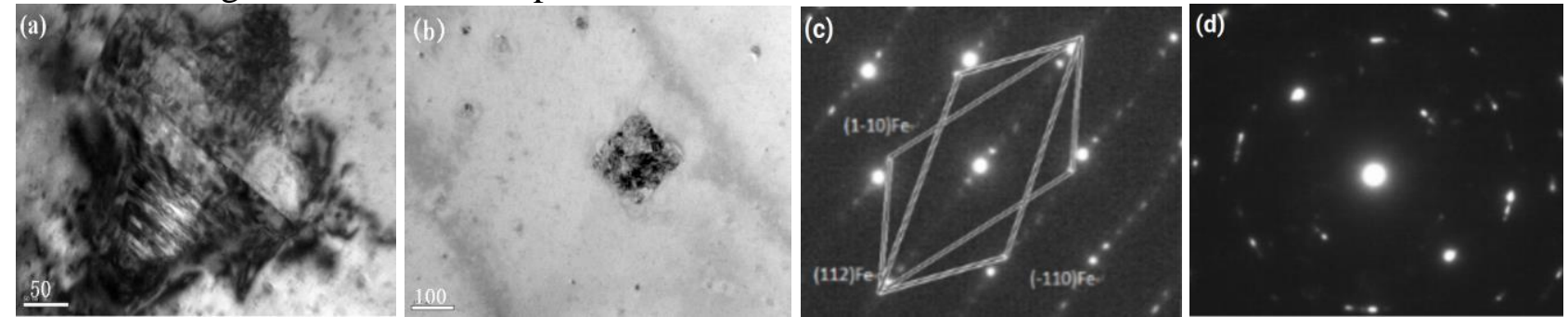

Fig. 6. The twin structure of Fe-rich phase

(a), (c) TEM images and diffraction spots of Fe-rich phase in $\mathrm{Cu}-1.5 \mathrm{Fe}$ alloy

(b), (d) TEM images and diffraction spots of Fe-rich phase in $\mathrm{Cu}-1.5 \mathrm{Fe}-0.5 \mathrm{Co}$ alloy

\section{Coherency relationship}

Using HRTEM (High-resolution TEM image) to further study the morphology and structure of the nanoparticles. Figure 7 (a) is a HRTEM photograph of two nanoparticles, size of the larger and circular nanoparticle (arrow A Points to) is about $16 \mathrm{~nm}$, size of the smaller and rectangular nanoparticle (arrow B Points to) is about $6 \mathrm{~nm}$. Crystal plane spacing of copper matrix surrounding nanoparticles is $0.208 \mathrm{~nm}$, it is consistent with the crystal plane spacing of copper (-11-1). Crystal plane spacing of the nanoparticle in Fig. 7 (a) is $0.201 \mathrm{~nm}$ equal to crystal plane spacing of iron (1-10). Fourier transformation and calibration directed to the precipitated phases in selected area, in figures, the strong brightness spots are copper matrix, the weaker brightness spots are precipitated Fe-rich phase. Mismatch between the matrix phase and the precipitated phase is calculated by the following formula with

$$
\sigma=2(\mathrm{~d} 1-\mathrm{d} 2) /(\mathrm{d} 1+\mathrm{d} 2)
$$

Where, $\sigma$ is a mismatch between the matrix phase and the precipitated phase; $\mathrm{d} 1$ and $\mathrm{d} 2$ are crystal plane spacing of the $\mathrm{Cu}$-matrix (-11-1) and Fe-precipitates (1-10). Calculating according to the formula (1), $\sigma=0.034$, it falls within the range of $0-0.05$ (criterion for coherent relationship), therefore, it can be considered that fully coherent relationship presence between $\mathrm{Cu}(-11-1)$ and $\mathrm{Fe}$ (1-10). 

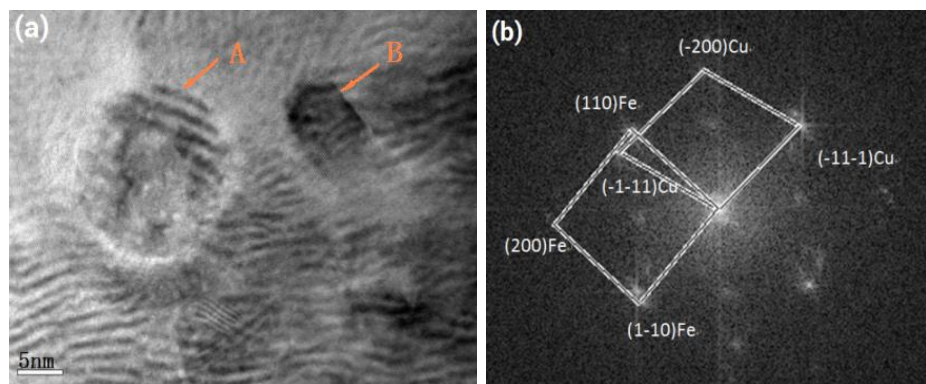

Fig.7. High-resolution TEM image and diffraction spots calibration of Fe-rich phase in $\mathrm{Cu}-1 \mathrm{Fe}$ alloy solidified in $3 \mathrm{~mm}$ diameter quartz tube

\section{Conclusion}

Nanoparticles of Fe-rich dispersed in copper alloy were obtained by experimental methods. Confirmed by adding elements $\mathrm{Fe}$ (1-3\%) and $\mathrm{Co}$ and by thermodynamic controlling, Fe-rich nanoparticles dispersed in matrix of the copper cast alloy can be obtained. It is proved that these Fe-rich nanoparticles and the $\mathrm{Cu}$-matrix phase remains coherency relationship.

\section{References}

[1] Uenishi K, Kawaguchi H, Kobayashi K F. Microstructure of Mechanically Alloyed A12In Alloys. Journal of Materials Science, 1994, 29 (18): 4860 4865

[2] Eppich R E, Webbere F J, Dawson R N. New Bearing Material Cast from Immiscible Metals. Metals Eng. Quart, 1971, 11 (1): 33 39

[3] Inoue A, Yano N. Microstructure and Superconducting Properties of Melt Quenched Insoluble Al-Pb and Al-Pb-Bi Alloys. J. Mater. Sci., 1987, 22: 123 128

[4] Wecker J, Von R, Helmolt etal. Giant Magnetoresistance in Melt Spun Cu2CoAlloys. Appl. Phys. Lett ., 1993, 52 (16): 1985 1987

[5] Richard N. Alloy Solidification in Systems Containing Liquid Miscibility Gap. Metall. Trans. A, 1982, 13A: 493 495

[6] Derby B, Camel D, Favier J. J. Temperature Gradient and Growth Velocity Effects on the Irregular Monotectic Structure. J. Cry. Growth, 1983, 65: 280 286

[7] Grugel N G, Hellawell A. Alloy Solidification in Systems Containing Liquid Miscibility Gap. Metall. Trans., 1981, 12A: 669 681

[8] Chen Q, Jin Z. The Fe-Cu system: A thermodynamic evaluation. Metallurgical and Materials Transactions A, 1995, 26(2): 417 426

[9] Mazumder P, Trivedi R, Karma A. A Model of convection-induced oscillatory structure formation in peritectic alloys [J]. Metall Mater Trans A, 2000, 31: 1233 1246 